\title{
Trabalho e classes sociais
}

\author{
FERNANDO HADDAD
}

RESUMO: Exposição, discussão e refutação das principais tentativas de atualizar a teoria marxista de classes e posterior reavaliação dessa teoria à luz da transformação da ciência em fator de produção e da possível perda de centralidade do trabalho no processo produtivo, tendo por base as interpretações lógicas da obra de Marx feitas por Ruy Fausto.

reio que uma estratégia teórica razoável para enfrentar o persistente problema da conceituação da categoria trabalho e das transformações do processo de trabalho nas sociedades contemporâneas seja passar em revista algumas das principais teses que, de um século para cá (desde a publicação do Livro III de $O$ capital) esforçam-se por compreender a estrutura de classes das sociedades contemporâneas: da sociologia alemã do começo do século aos recentes estudos do marxismo analítico, passando pelo austro-marxismo, pelo pensamento francês da década de 60, pelos trabalhos dos teóricos anglofônicos, pela produção leste-européia etc. Afinal, mal ou bem, todas essas teses sobre classes sociais, defendidas com brilho pelos principais sociólogos do século, encontram seu fundamento último no acompanhamento da evolução dos processos de trabalho, ou mais propriamente, na forma como a sociedade se reproduz do ponto de vista material.

Contra isso, pode-se argumentar que o fato de que nenhuma dessas teses tornou-se hegemônica, a ponto de gozar do prestígio que a teoria de classes marxista conheceu, indica que as visíveis deficiências desta última no que diz respeito à explicação da dinâmica do capitalismo recente possam ser insuperáveis a partir de um ponto de vista centrado no conceito de classe social. É bem verdade que os progressos no campo de estudo das classes não são, de

UNITERIMOS: classes sociais, trabalho, ciência, marxismo.
Professor do Departamento de Ciência Política da FFLCHUSP 
maneira nenhuma, negligenciáveis. Conceitos como os de "nova classe média" (Lederer), "setor terciário ou de serviços" (Clark), "sociedade pós-industrial" (Bell) etc. são referências obrigatórias para o estudioso que ousar entrar para o debate, ainda que para rejeitá-los. Mas é igualmente certo que as divergências entre os teóricos são apreciáveis, desencorajando aquele que pretenda apresentar uma nova alternativa para o problema. Contudo, na ciência como na vida, os obstáculos são tão mais atraentes quanto maior a dificuldade em transpô-los.

Preliminarmente, convém esclarecer que considero o assunto "classe social" um objeto próprio da economia política (e secundariamente da sociologia ou da ciência política). Diga-se, antes de mais nada, que esse era também o entendimento de Marx. Com efeito, rigorosamente falando, o conceito de classe social em sentido pleno é definido, dentro do discurso de Marx, pelas relações de distribuição que são expressão imediata das relações de produção. Isto significa que quando Marx se refere às três grandes classes, a dos trabalhadores assalariados, a dos capitalistas e a dos proprietários fundiários, não está ele querendo dizer que existam outras "pequenas camadas" dignas do nome "classe". Embora Marx use esta denominação para se referir a outros grupos distintos dos "três grandes", tudo leva a crer que, do ponto de vista da dinâmica do sistema, a ele só interessava estudar as tendências relativas ao comportamento daqueles grupos imediatamente ligados ao processo de reprodução material da sociedade. De resto, esta é a única posição compatível com um materialismo histórico fundado no paradigma da produção. Esse é o motivo pelo qual Marx, por exemplo, apesar de prever (como veremos) o aumento numérico relativo dos serviçais domésticos ou dos funcionários de Estado, não lhes dedica atenção especial. Se a palavra "grande" da expressão "grandes classes" dissesse respeito ao aspecto numérico da questão, este grupo, decerto maior do que o grupo dos capitalistas ou proprietários fundiários, mereceria uma maior consideração.

Dito isso, podemos iniciar nossa análise pela teoria marxista clássica das classes, sem perder de vista, obviamente, a contribuição dos estudiosos que se debruçaram sobre o assunto. Deixando de lado a caracterização e distinção da classe dos capitalistas e dos proprietários fundiários, questões menos problemáticas, comecemos pelo que nos interessa imediatamente: $o$ conceito de "classe dos trabalhadores assalariados". No que segue contaremos com o apoio dos estudos de Ruy Fausto, particularmente o ensaio "Sobre as Classes", publicado em Marx: lógica e política, Tomo II. Fausto propõe duas questões sobre o tema, às quais acrescento uma terceira. A primeira questão remete ao problema de saber até que limite um trabalhador qualificado pertence à classe dos trabalhadores assalariados. A segunda questão consiste em saber se este conceito de trabalhadores assalariados compreende tanto os trabalhadores improdutivos, interiores e exteriores à produção, quanto os trabalhadores produtivos. A terceira questão consiste em pesquisar até que ponto o proletário despossuído dos meios de produção, do ponto de vista da 
sua atividade ou inatividade, ou seja, do seu emprego ou desemprego, mantém sua condição de trabalhador. A partir das respostas a estas três perguntas coloca-se o problema, que é o que particularmente nos interessa, sobre as tendências do sistema no que se refere à estrutura de classes.

Passemos à primeira questão, talvez a mais espinhosa e à qual daremos, por enquanto, apenas uma resposta preliminar: a questão da qualificação. Até que ponto um nível superior de salário ou algum tipo de poder numa organização capitalista são atributos incompatíveis com a condição de membro da classe dos trabalhadores assalariados? Fausto, inspirado na lógica hegeliana, ensina que as situações possíveis podem ser representadas por três níveis que correspondem aos conceitos de identidade, de diferença $\mathrm{e}$ de contradição. "No primeiro nível, ensina Fausto, diríamos 'o trabalhador assalariado é o possuidor da força de trabalho simples'; ou 'o trabalhador assalariado é pura e simplesmente subordinado à autoridade do capitalista'; ou 'o trabalhador assalariado recebe um salário que permite a conservação do indivíduo que trabalha na sua condição normal de vida'. Nos três casos, o predicado corresponde ao sujeito, temos juízo de inerência. Num segundo nível, continua Fausto, não é mais a identidade que é posta, mas a diferença. Diríamos: 'o trabalhador assalariado é o trabalhador qualificado'; ou 'o trabalhador assalariado está submetido ao capitalista, mas, por sua vez, submete em tal ou qual grau (intensivo ou extensivo) outros trabalhadores assalariados'; ou 'o trabalhador assalariado recebe um salário (bem) superior ao necessário à conservação e reprodução do indivíduo enquanto trabalhador assalariado'. Nesse caso, o sujeito está pressuposto, só o predicado está posto. O juízo é de reflexão, mas não há contradição, só diferença, contrariedade se se quiser entre sujeito e predicado. No terceiro caso, conclui Fausto, temos um enunciado que corresponde a um juízo do devir (embora não exprima um devir efetivo). Não só o sujeito é pressuposto e o predicado posto, mas o segundo contradiz o primeiro: 'o trabalhador assalariado o manager'" (cf. Fausto, 1987, p. 228 ss). Essa passagem do ensaio de Fausto ajuda a evitar muita confusão conceitual. Repare-se que, num primeiro momento ela distingue trabalho simples de trabalho qualificado não gerencial. Num segundo momento, entre trabalho (qualificado ou não) e gerência (management).

Subjacente ao problema da diferença (e não contradição) entre trabalho simples e trabalho qualificado está a questão, que consumiu muito tinta, da redução, operada pela teoria marxista do valor, deste àquele. Com efeito, Marx estabelece que o trabalho qualificado não é senão uma potência do trabalho simples, acrescentando que, na grande indústria capitalista mecanizada, ao contrário da manufatura, há uma tendência a reduzir e igualar todos os tipos de trabalho a um mesmo nível. Esse raciocínio (que Marx compartilha com Ure e Proudhon contra Smith e Babbage) dividiu os estudiosos. Por um lado, houve quem (por exemplo, Dahrendorf) questionasse a tendência à homogeneização da classe trabalhadora, propondo, justamente, $\mathrm{o}$ movimento inverso: o de diferenciação progressiva e conseqüente decompo- 
sição do trabalho. Por outro lado, houve quem (por exemplo, Braverman, baseando-se nos estudos empíricos de James Bright) defendesse a tendência originalmente proposta por Marx.

Contudo, tenho para mim que o problema da redução do trabalho qualificado ao trabalho simples não passa pela questão objetiva da tendência à desqualificação ou não da força de trabalho (que não deixa de ser interessante), mas diz respeito, mais propriamente, à questão do caráter da reprodutibilidade da força de trabalho, seja qual for a sua utilização. A força de trabalho, qualificada ou não, reproduz-se, sob o capitalismo, de uma maneira totalmente distinta do virtuose medieval. A pessoalidade cede lugar à impessoalidade. Essa verdadeira anonimização do processo de reprodução da força de trabalho (independente da qualificação) operada pelo capitalismo expressa-se, com uma clareza absoluta, na placa de "procura-se..." exposta nas fachadas das empresas ou nos classificados de jornal. Por raro que seja o profissional procurado, o próprio mercado de trabalho, em condições normais, cuida de produzi-lo sem a interferência do capitalista que, em geral, só tratará de treiná-lo para conformá-lo às peculiaridades da sua organização. Essa tendência de anonimização só se modifica quando a Ciência passa à condição de fator de produção e fundamento da riqueza, tema que abordaremos oportunamente; neste caso, como veremos, já se ultrapassa o debate sobre qualificação do trabalho porque se ultrapassa, no fundo, o próprio conceito de trabalho. Aqui, não se trata da mera negação da forma, mas da negação da própria essência do modo capitalista. É esta negação da essência que, como se estudará, fundamenta todas as negações da forma aparentemente adequada ao sistema ou, se se quiser, faz da forma negada a forma adequada ao modo de produção capitalista.

Deixando de lado, por ora, esta problemática, passemos adiante. Quanto ao problema da contradição (e não simples diferença) entre trabalho e gerência, as divergências entre os teóricos não são menores. Essas divergências derivam do caráter contraditório do trabalho diretivo do gerente. Por um lado, o gerente é um trabalhador assalariado. Enquanto tal, sua remuneração deve ser o salário de mercado pago por um certo tipo de trabalho qualificado. Mas, por outro lado, no que se refere às funções que o gerente desempenha, tem-se que o seu trabalho é um tipo de trabalho ligado à exploração. Este trabalho de comando, na medida em que resulta da forma específica da produção capitalista, produz valor e, por conseguinte, mais-valia, mas, ao mesmo tempo, está ligado à função de apropriar-se do trabalho alheio. Há contradição, portanto, tanto em relação ao trabalhador quando em relação ao capitalista. Os gerentes pertencem a uma categoria que está fora das grandes classes, mas está próxima da classe dos proprietários do capital. Sua existência, contudo, pressupõe a separação entre propriedade e função do capital, o que de certa forma neutraliza a classe dos capitalistas. Marx e os marxistas supuseram que esta condição prenunciava um período de transição para fora da ordem capitalista. Outros teóricos (Burnham, Dahrendorf, Galbraith, etc.) preferiram acreditar que a camada dos gerentes já representava a classe dominante de uma ordem pós- 
capitalista. Não obstante, a separação de função e propriedade do capital revelou-se tão-somente a forma "mais adequada" que potencializa o processo da sua reprodução ampliada.

Quanto à segunda questão, sobre a abrangência do conceito de trabalhadores assalariados relativamente à produtividade ou improdutividade do trabalho executado, há, primeiramente, que se fazer uma distinção entre trabalhadores improdutivos exteriores à produção e trabalhadores improdutivos que se situam no interior do processo global de produção. No primeiro caso, o trabalhador vende sua força de trabalho em troca de um "salário", mas não a vende ao capital. Deste grupo fazem parte, basicamente, os assalariados do Estado e os domésticos. O "salário" que estes trabalhadores recebem, na verdade, é o resultado de uma redistribuição dos rendimentos percebidos pelas três grandes classes do sistema, os proprietários da força de trabalho que a vendem ao capital, os proprietários do capital e os proprietários da terra, cujos rendimentos são o salário, o lucro e a renda da terra, respectivamente. Feita essa distinção, tomado o conceito de classe na acepção proposta, segue-se que estes trabalhadores improdutivos exteriores à produção, embora trabalhadores assalariados, não pertencem à classe dos trabalhadores assalariados.

No segundo caso, o dos trabalhadores improdutivos que se situam no interior do processo de produção, isto é, assalariados que vendem sua força de trabalho ao capital, seja capital comercial, capital financeiro ou capital industrial (mas para executar tarefas comerciais ou financeiras), passa-se algo diferente. Apesar de improdutivos, estes trabalhadores, pelo fato de o serem no interior da esfera do processo global de produção, fazem parte da classe dos trabalhadores assalariados. Seu rendimento deriva imediatamente das relações de produção.

Em todos esses casos, os problemas teóricos a enfrentar são grandes. Os trabalhadores improdutivos interiores ao processo de produção foram apelidados pela literatura sociológica de "trabalhadores em escritório". Essa categoria compõe, agregada à outras, o que alguns teóricos chamam de "nova classe média" ou "classe de serviços". O vertiginoso aumento numérico desta camada, absoluto e relativo, serviu de munição preciosa aos críticos da teoria marxista. A situação agravou-se, ademais, porque os críticos não raramente somavam o número dos "trabalhadores em escritório" ao número, também crescente, dos "funcionários públicos”. Certamente, inspiraram-se em Weber para quem "constitui um erro supor que o trabalho intelectual da oficina se distinga, no mínimo detalhe, daquele do despacho estatal. Antes, ambos são essencialmente homogêneos. Do ponto de vista da sociologia, o Estado moderno é uma 'empresa' com o mesmo título que uma fábrica” (Weber, 1992, p. 1061). Contudo, se adotada a terminologia até aqui defendida, os funcionários públicos sequer poderiam ser considerados membros da classe dos trabalhadores assalariados ou de qualquer outra classe.

De fato, Marx jamais manifestou a crença de que poderia haver um aumento relativo destes trabalhadores em escritório em relação ao conjunto 
dos assalariados, embora tivesse previsto um aumento absoluto que pudesse até ensejar uma certa divisão de trabalho no escritório. Essa previsível divisão do trabalho associada à esperada universalização do ensino público, que faria com que essa camada perdesse alguns de seus privilégios originais (status, remuneração, poder) por conta do conseqüente aumento de oferta desse tipo de trabalho, sugeria um quadro em que o problema não tinha relevância.

As coisas, porém, tiveram outra evolução. Ainda no século passado, Charles Booth criticava o conceito marxista de força de trabalho média indiferenciada na qual, segundo ele, Marx baseava sua gigantesca falácia, justamente apelando para o exemplo dos trabalhadores em escritório. Contudo, os dados estatísticos indicam que, se Marx estava errado em relação ao aspecto numérico do problema (houve, como salientou Weber, um aumento relativo expressivo do número dos improdutivos interiores à produção), estava parcialmente certo em relação ao problema do status (só uma parcela diminuta destes trabalhadores goza, devido à intensa divisão do trabalho que o escritório moderno experimentou, dos privilégios que essa camada detinha, no seu todo, originalmente).

No século XIX, a meia dúzia de trabalhadores em escritório que só as maiores empresas possuíam, em termos de função, poder, remuneração e estabilidade estavam muito mais próximos do empregador do que do trabalhador da fábrica. Em geral, esses trabalhadores executavam funções típicas empresariais como contabilidade, contratação de pessoal, compra de matéria-prima e bens de capital, venda do produto acabado, abertura de crédito junto às instituições financeiras, aplicações financeiras, concessão de crédito a clientes etc. Cabe observar que nenhuma dessas funções, no jargão marxista, produz valor, distinguindo-se, portanto, do trabalho de gerência, estudado acima, enquanto trabalho de comando do trabalho produtivo, embora a divisão do trabalho de escritório faça surgir a figura do improdutivo gerente de escritório.

Todavia, todas essas funções improdutivas ganham importância considerável no capitalismo contemporâneo. Um fato inquestionável é que, em 1970 nos EUA, mais de 30\% do total da força de trabalho empregada pelas indústria compunha-se de empregados de escritório. Se considerarmos que a indústria, naquele ano, empregava cerca de $25 \%$ do total dos assalariados (incluindo os exteriores à produção), temos que mais de $8 \%$ da força de trabalho total daquele país empregava-se nos escritórios das indústrias. Somando-se a isso os cerca de $25 \%$ dos trabalhadores no comércio e nas finanças, chega-se à conclusão de que cerca de $1 / 3$ da força de trabalho total era composta de empregados em escritório. Se acrescentarmos a este número (como faz Renner, adotando uma conceituação de classe imprecisa) o total de funcionários públicos (portanto, os trabalhadores improdutivos exteriores à produção, com exceção dos domésticos), chegamos aos 50\%. Um número impressionante comparado ao número de operários: cerca de $35 \%$.

Há, contudo, um outro lado da questão. Como observou Hans Speier, 
já em 1934, "o nível social do empregado assalariado [de escritório - FH] baixa com a extensão crescente do grupo" (apud Braverman, 1987, p. 295). Aqui também não poderia deixar de vigorar o princípio de Babbage, que foi quem primeiro percebeu o fato simples, mas que passou despercebido por Adam Smith, de que dividir o trabalho não apenas aumenta sua produtividade (efeito destacado por Smith), mas sobretudo barateia suas partes individuais (fato tão ou mais importante que o primeiro numa sociedade baseada na compra e venda da força de trabalho).

Assim, a partir de 1917, com os trabalhos de Leffingwell e Galloway, os princípios do sistema taylorista de gerência científica começam a ser aplicados na gerência de escritório. $\mathrm{O}$ trabalho em escritório, inicialmente associado à idéia de trabalho mental, contrapunha-se, até então, ao trabalho meramente manual. Mas logo se percebeu, sem dúvida graças a Taylor, que o trabalho mental quase necessariamente assume forma num produto externo, além de exigir uma série de operações manuais prévias. É, pois, possível e desejável que se separe as funções de concepção e execução. Pode-se escrever uma carta ou ditá-la a uma estenodatilógrafa. Pode-se, pessoalmente, entregar um memorando a um colega de trabalho ou contar com uma equipe que funcione como correio interno. Pode-se ter de arquivar documentos, apontar lápis, digitar os números de um telefone, comprar um lanche ou servir-se café etc. etc. etc. ou ter alguém que faça isso tudo, liberando alguém qualificado para compor um grupo cada vez mais reduzido de pessoas que exercem as funções de pensamento e planejamento. Se assim é, a aplicação dos princípios tayloristas ao trabalho de escritório deveria provocar uma queda considerável dos ganhos médios dessa camada de assalariados, o que as estatísticas confirmam ser o caso. Diante disso, Wright Mills, por exemplo, muito à maneira das análises de James Bright sobre mecanização do processo de produção, conclui, em seu White collar (1951), que o efeito inicial de especializar mais os indivíduos quando da introdução de uma nova divisão do trabalho em escritório é posteriormente anulado pela fragmentação e mecanização de todas as tarefas que, afinal, estreitam-se.

A partir dessas considerações, duas tendências teóricas verificaramse. A primeira, representada por Dahrendorf (1957) e Braverman (1974), buscou recolocar na ordem do dia a visão dicotômica de sociedade de classes: este, mediante a defesa da teoria marxista original, recuperando a oposição clássica entre capital e trabalho; aquele, recusando esta oposição em virtude da decomposição do capital (função versus propriedade) e da decomposição do trabalho (heterogeneidade da força de trabalho) e, na esteira dos trabalhos de Djilas e Burnham, reformulando a teoria dicotômica de classes por meio dos conceitos de classe dirigente e classe dirigida (corte que, no seu entender, passa tanto pela fábrica quanto pelo escritório, bem como por qualquer associação imperativamente coordenada - Herrschaftsverband - uma categoria weberiana).

A segunda tendência, mais interessante, mas ainda insatisfatória, representada, por exemplo, por Giddens (1973) e pelo marxista analítico E. 
O. Wright (1984), buscou recolocar mais uma vez, não sem trazer novos elementos para o debate, o conceito de classe média (aparentemente comprometido no âmbito da oposição entre trabalho produtivo na fábrica e trabalho improdutivo no escritório), para o âmbito da oposição entre trabalho qualificado e trabalho não-qualificado. Giddens abandona a posição dicotômica centrada na propriedade ou não dos meios de produção, introduzindo o conceito weberiano de habilidade vendável. Segundo Giddens, Marx fracassou em reconhecer o significado potencial das diferenciações de possibilidade de mercado, o que inclui habilidades reconhecidas que podem ser vistas como propriedades que se trocam no mercado. A partir daí, Giddens faz uma interessante distinção entre estruturação mediata e estruturação imediata de classes. "Pelo primeiro termo, diz Giddens, refiro-me a fatores que intervêm entre a existência de certas possibilidades de mercado e a formação de classes como grupamentos sociais identificáveis" (Giddens, 1975, p. 128). Giddens identifica três tipos de possibilidades de mercado: a propriedade dos meios de produção, a posse de qualificações técnicas ou educacionais e a posse de força de trabalho manual. Isso produz o fundamento para um sistema de três classes: alta, média e baixa (ou classe trabalhadora). Mas há ainda três fontes de estruturação imediata de classes que se referem a fatores que condicionam ou moldam a formação de classes. São eles: a divisão do trabalho, as relações de autoridade e a influência de grupamentos distributivos. A primeira fonte de estruturação tende a produzir uma separação entre as condições de trabalho de trabalhadores manuais e não-manuais. A isso sobrepõe-se o sistema de autoridade típico das empresas (segunda fonte de estruturação). Uma terceira fonte refere-se ao padrão de consumo como uma influência adicional na estruturação de classes (ainda que Giddens concorde com Marx sobre a idéia de que classe seja um fenômeno da produção e não do consumo). Quando as estruturações de classes mediata e imediata se sobrepõem, como é o caso da sociedade capitalista, as classes existem como formações distinguíveis. Essa análise, segundo Giddens, tem a vantagem adicional de explicar a situação intermediária de algumas camadas sociais, como o da pequena burguesia: "se for o caso de que as chances de mobilidade da pequena para a grande posse de propriedade (...) sejam pequenas, é provável que se isole o pequeno proprietário da filiação da classe mais alta como tal. Mas, o fato de desfrutar o controle diretivo de uma empresa, por menor que seja, atua no sentido de diferençá-lo daqueles que são parte de uma hierarquia de autoridade numa organização maior. Por outro lado, a renda e outros benefícios econômicos da pequena burguesia talvez sejam semelhantes aos do trabalhador white-collare, portanto, podem pertencer a grupamentos distributivos semelhantes" (Giddens, 1975, p. 132).

Wright, por seu turno, abandona a posição dicotômica entre trabalho e capital da seguinte maneira. A exemplo de outro marxista analítico, John Roemer, Wright baseia seu conceito de exploração nas iniqüidades de distribuição de ativos produtivos. Com uma diferença: aos dois ativos 
considerados por Roemer, ativos físicos (alienáveis) e ativos de habilidades (inalienáveis), Wright acrescenta outros dois - ativos de força de trabalho e ativos de organização. As iniqüidades na distribuição de ativos físicos (meios de produção) caracterizam a sociedade capitalista. As iniqüidades na distribuição de ativos de força de trabalho caracterizam a sociedade feudal (um senhor dispõe de vários servos que, por sua vez, dispõem, individualmente considerados, de menos do que uma unidade de força de trabalho, no caso, parte da sua própria). As iniqüidades em ativos de organização, baseadas em diferentes posições dentro de uma hierarquia de autoridade, caracterizam o socialismo burocrático-estatal. Por fim, as iniqüidades na distribuição de ativos de habilidades (skills) caracterizariam as sociedades socialistas futuras.

Como as sociedades, segundo Wright, dificilmente podem ser caracterizadas por um único modo de produção, há posições que, no que diz respeito a uma dimensão de exploração, são exploradoras e, no que diz respeito à outra, são exploradas. Neste contexto, temos o caso dos profissionais altamente bem remunerados: "eles são explorados capitalisticamente porque eles carecem de ativos de capital e ainda assim são exploradores pelas habilidades que possuem" (Wright, 1977, p. 126). É esta condição dúplice que faz deles uma classe média dentro do sistema.

O problema da posição de Giddens e Wright diz respeito ao conceito de habilidades vendáveis. Wright tenta defini-lo: "habilidade (skill) nesse contexto não é um conceito trivial. A mera possessão de capacidades aprimoradas de trabalho adquiridas por meio de treinamento não é suficiente para gerar relações de exploração, já que a renda de tal trabalho treinado deve refletir os custos de adquirir o treinamento. Em tais casos não há nem uma transferência de mais-valia, nem o destreinado estaria melhor sob a especificação jogo-teórica de exploração se as habilidades fossem redistribuídas. Para que uma habilidade seja a base de exploração, portanto, ela deve ser em algum sentido escassa relativamente à demanda e deve haver algum mecanismo por meio do qual os proprietários individuais de habilidades escassas sejam capazes de traduzir essa escassez em maior renda" (Wright, 1977, p. 125). Ora, o que fica claro é que, estas habilidades não estão sujeitas às regras do mercado de trabalho convencional. Nem mesmo estão sujeitas ao padrão de reprodutibilidade da força de trabalho nos marcos do capitalismo clássico. Porém, ainda que a intenção de Giddens e Wright seja, ao que parece, tentar estabelecer uma diferença importante entre estas habilidades e o trabalho qualificado na forma tratada originalmente por Marx, eles não enfrentam o desafio de frente.

Por ora, de tudo o que se falou, só podemos concluir, mantendo-nos fiéis ao conceito de classe de Marx, que a classe dos trabalhadores assalariados compreende os trabalhadores improdutivos, mas não todos os trabalhadores improdutivos: os improdutivos exteriores à produção (funcionários públicos e domésticos) estão excluídos. Quanto a estes últimos, há um comentário de Marx sobre o aumento relativo do seu número que merece destaque. Marx 
esclarece: "se os trabalhadores produtivos são os que são pagos pelo capital e trabalhadores improdutivos, os que são pagos pelo rendimento, é evidente que a classe produtiva se relaciona com a improdutiva como o capital com o rendimento. Entretanto, o crescimento proporcional das duas classes não dependerá somente da relação existente entre a massa de capitais e a massa de rendimentos. Ele dependerá da proporção em que o rendimento (lucro) crescente se transforma em capital ou é gasto enquanto rendimento. Embora originalmente a burguesia fosse muito econômica, com a produtividade crescente do capital, isto é, dos trabalhadores, ela imita o sistema de retainers dos feudais". Ao que Marx acrescenta: "que bela organização que faz suar uma jovem operária durante 12 horas numa fábrica, para que o dono da fábrica possa empregar, com uma parte do trabalho não pago dela, para o seu serviço pessoal, a irmã dela como criada, seu irmão como valet de chambre e o seu primo como soldado ou policial" (apud Fausto, 1987, p. 269).

Quanto à qualificação temos algo parecido. A classe dos trabalhadores assalariados compreende os trabalhadores qualificados, mas não todos os trabalhadores qualificados: o trabalho do manager é caracterizado como função de exploração; ele é "trabalhador", mas trabalhador enquanto capitalista, o que, se não o torna um capitalista, o aproxima da classe dos proprietários do capital. Haverá, contudo, no capitalismo avançado, alguma outra categoria qualificada que não esteja compreendida no conceito de classe trabalhadora, embora se venda ao capital?

O problema permanecerá, por enquanto, em aberto. Antes de enfrentá-lo definitivamente, tomemos uma última questão sobre a abrangência da classe dos trabalhadores assalariados, agora no que diz respeito ao emprego ou desemprego da força de trabalho. Em primeiro lugar, é preciso notar que a acumulação de capital se caracteriza por um processo de concentração e centralização. Como corolário, temos o crescimento de um contingente da população, denominado exército industrial de reserva, cuja dimensão depende das fases dos ciclos econômicos, mas que, tendencialmente, aumenta em termos absolutos, mas também relativamente ao conjunto do proletariado. Com o aumento do exército industrial de reserva, que, a rigor, pertence à classe trabalhadora, uma vez que se caracteriza pela expectativa de se ver reincorporado ao contingente dos trabalhadores em atividade, aumenta também o contingente da população desclassificada, o lumpemproletariado, que se distingue do exército industrial de reserva porque, neste caso, não há a possibilidade desse contingente ser reabsorvido pelo mercado de trabalho. Essa condição coloca o lumpemproletariado fora do conceito de classe trabalhadora, entre outras coisas porque, como Marx notou no Manifesto e no 18 Brumário, "sua condição de vida o predispõe mais a vender-se à reação". A relação entre proletariado, exército industrial de reserva e lumpemproletariado pode ser mais bem focalizada se nos utilizarmos das mesmas categorias lógicas que aplicamos à questão do "nível de salário e poder" entre os assalariados produtivos, quais sejam, identidade, diferença e contradição, e as aplicarmos à questão do 
emprego (Fausto não faz esse desenvolvimento). Percebe-se que no juízo “o proletário é o lúmpen” não só o predicado está posto e o sujeito pressuposto, como também o predicado contradiz o sujeito. Não é o que acontece com o juízo "o proletário é o desempregado", onde há diferença entre sujeito e predicado, uma vez que a condição de proletário exige que este venda sua força de trabalho; mas não há contradição, em virtude da expectativa de que isso ocorra na fase de expansão econômica. Já no juízo “o proletário é o empregado" só há identidade. Aqui também tem-se que a classe dos trabalhadores assalariados compreende os despossuídos, mas não todos os despossuídos: o lumpemproletariado está excluído.

Sobre este tema ainda, seria importante lembrar o conceito de "nãoclasse dos não-trabalhadores" proposta por Gorz em Adeus ao proletariado (1980). Sob essa denominação, Gorz parece incluir o exército de reserva e o lumpemproletariado. Nos seus próprios termos: "essa não-classe engloba, na realidade, o conjunto dos indivíduos que se encontram expulsos da produção pelo processo de abolição do trabalho, ou subempregados em suas capacidades pela industrialização (ou seja, pela automatização e pela informatização) do trabalho intelectual. Engloba, continua Gorz, o conjunto desses extranumerário da produção social que são os desempregados reais e virtuais, permanentes e temporários, totais e parciais. É o produto da decomposição da antiga sociedade fundada no trabalho: na dignidade, na valorização, na utilidade social, no desejo do trabalho. Estende-se a quase todas as camadas da sociedade, e abrange muitos além daqueles que os Panteras Negras, no final da década de 1960, chamavam nos Estados Unidos, de lúmpen ${ }^{1}$ e, com uma antevisão notável, opunham-nos à classe dos operários estáveis, sindicalizados, protegidos por um contrato de trabalho e por uma convenção coletiva (cf. Gorz, 1987, p. 87-88).

Esses trabalhadores acidentais que ocupam empregos precários para os quais podem até mesmo ser superqualificados, estando condenados ao desemprego dos seus conhecimentos muitas vezes aprendidos em escolas e faculdades, não se sentem pertencer à classe dos operários ou a qualquer outra. Ao contrário destes, esses não-trabalhadores são subjetivamente liberados: procuram conquistar sua autonomia para além do gerenciamento dos aparelhos, subtraindo-se à lógica produtivista da sociedade capitalista. Num contexto onde se produz para trabalhar ao invés de se trabalhar para produzir, o trabalho ele mesmo é atingido de não-sentido. Para Gorz, essa lógica levou a humanidade ao limiar da liberação, mas que só será transposto pela decomposição da ética do trabalho, pela recusa da ética da acumulação e pela dissolução das classes. Apenas a não-classe dos não-trabalhadores, segundo Gorz, é capaz desse ato fundador.

É curiosíssimo notar que esta tese de Gorz visava, entre outras coisas, refutar um outra tese defendida por ele próprio, em Estratégia operária e neocapitalismo (1964) e por Serge Mallet, em La nouvelle classe ouvrière (1963). Mallet, num instigante estudo sobre a indústria automatizada, observou
Conceito usado por eles num sentido já mais amplo que o marxista. 
a existência de dois tipos de trabalhadores assalariados dentro dessa organização. 1) De um lado, dois grupos, "os vigias, encarregados, operadores, conectados às unidades de produção automatizadas e os trabalhadores de manutenção, encarregados do reparo e da vigilância dos mecanismos da maquinaria". A automação exige dos primeiros um conhecimento completo do setor do processo de produção no qual estão inseridos, enquanto exige dos últimos uma visão global de todos os setores. Não obstante essa diferença, dentro da nova unidade de produção automatizada, os trabalhadores são integrados de uma forma inédita. Observa-se ainda, segundo Mallet, uma hierarquização entre eles, só que desta vez no interior de um mesmo grupo social. Há uma homogeneização do trabalho, mas nivelado por cima. A automação destrói a parcelização do trabalho e constitui, ao nível da equipe, a visão do trabalho polivalente. 2) De outro lado, devotados à pesquisa e ao estudo, à comercialização etc., encontram-se os "técnicos do escritório de estudos". Apesar da separação física destes trabalhadores dos operários da fábrica e apesar do sentimento de superioridade que anima aqueles, as condições de trabalho nas unidades intelectuais de produção, com a mecanização do escritório, a rotinização das tarefas e a submissão dos talentos à lógica da acumulação, assemelham-se às condições experimentadas pelos operários. Ao que o Gorz de 1964 acrescenta: "técnicos, engenheiros, estudantes, pesquisadores descobrem que são assalariados como os outros (...). Descobrem que a pesquisa a longo prazo, o trabalho criador de soluções originais, a paixão pela profissão, são incompatíveis com os critérios de lucratividade capitalista (...). Descobrem-se subordinados à lei do capital, não somente no trabalho, mas em todas as esferas da vida" (Gorz, 1968, p. 111). Sem dúvida Gorz tem em mente o fato, sublinhado por Weber, de que o capitalismo operou "uma separação entre a massa dos pesquisadores (...) e seus 'meios de produção', análoga à que tem lugar na empresa capitalista entre os trabalhadores e os mesmos meios" (Weber, 1992, p. 738). Além disso, voltando a Mallet, as diferenças que eventualmente persistem entre as duas categorias, como remuneração diferenciada, não transformam os técnicos de escritório em uma aristocracia do trabalho, mas em modelos para os demais trabalhadores. Estas condições permitem a Mallet abrigar as duas categorias por ele observadas sob a mesma rubrica de "nova classe operária".

O Gorz de 1980 rompe com esta doutrina. E com o seguinte argumento: "[Marx] acreditava ter finalmente encontrado, no operário politécnico, a figura do proletário reconciliado com o proletariado, do sujeito da história encarnado em um indivíduo de carne e osso. Ora, Marx enganouse. E, na sua esteira, enganaram-se todos os que pensavam ${ }^{2}$ que o aperfeiçoamento das técnicas de produção e sua automatização iriam suprimir o trabalho não-qualificado, deixando subsistir apenas trabalhadores técnicos de nível relativamente elevado, com uma visão global dos processos técnicos e

Gorz inclui a si próprio numa nota de rodapé. capazes de autogerir a produção. Sabe-se [conclui Gorz] que ocorreu exatamente o contrário" (Gorz, 1987, p. 39). 
O pobre Marx, outrora criticado por ter previsto a desqualificação do trabalho com o desenvolvimento da indústria, é agora acusado de ter previsto uma qualificação que não aconteceu. Infelizmente, não ocorreu a Gorz (ou a Mallet) uma hipótese bastante verossímil defendida, por exemplo, por Daniel Bell: a de que houve uma cisão irrevogável no seio da classe assalariada. Divirjo de Bell, não obstante, no que concerne à natureza dessa cisão. Para elucidar definitivamente esta questão da qualificação, tomarei os próprios textos de Marx, analisados com brilho por Fausto em A pós-grande indústria nos Grundrisse (1989), para oferecer uma alternativa.

Antes de mais nada, convém relembrar a apresentação clássica do movimento do capital. Até um certo ponto da apresentação de Marx, capitalistas e trabalhadores encontram-se livremente no mercado dispostos a trocar aquilo que cada um dispõe, o primeiro, uma determinada quantidade de dinheiro, $o$ segundo, a mercadoria força de trabalho. E o fazem, respeitando estritamente o princípio geral da troca de equivalentes, pelo qual as mercadorias se trocam pelo trabalho socialmente necessário a sua reprodução. No entanto, quando se passa à análise do processo de acumulação, o movimento contínuo do capital perde seu caráter aparentemente fortuito e a própria liberdade de contrato se reduz a simples aparência. Perde-se, assim, a própria noção de troca de equivalentes e, o que assim parecia, se revela apropriação sem equivalente do trabalho alheio. Pelo menos até a grande indústria, o fundamento da riqueza continua sendo a massa de tempo de trabalho utilizado na produção. Assim, Marx estabelece: "a troca do trabalho vivo contra trabalho objetivado, isto é, a posição do trabalho social na forma da oposição entre capital e trabalho -é o último desenvolvimento da relação valor, e da produção que repousa sobre o valor. Sua pressuposição é e permanece - a massa de tempo de trabalho imediato, o quantum de trabalho utilizado como fator decisivo da produção da riqueza" (apud Fausto, 1989, p. 50).

Contudo, a continuação deste trecho dos Grundrisse é surpreendente. Marx prossegue: "mas à medida que a grande indústria se desenvolve, a criação da riqueza efetiva se torna menos dependente do tempo de trabalho e do quantum de trabalho utilizado, do que da força dos agentes que são postos em movimento durante o tempo de trabalho, poder que por sua vez - sua poderosa efetividade- não tem mais nenhuma relação com o tempo de trabalho imediato que custa à sua produção, mas depende antes da situação geral da ciência, do progresso da tecnologia, ou da utilização da ciência na produção" (Fausto, 1989, p. 50). Em seguida, Marx acrescenta: "a riqueza efetiva se manifesta (...) numa desproporção monstruosa entre o tempo de trabalho empregado e seu produto, assim como na desproporção qualitativa entre o trabalho reduzido a uma pura abstração e o poder do processo de produção que ele vigia”. Finalmente, conclui: “o trabalho não aparece mais até o ponto de estar incluído no processo de produção, mas o homem se relaciona antes como guardião e regulador do próprio processo de produção" (Fausto, 1989, p. 50). 
Ora, se assim é, o desenvolvimento da superindústria ${ }^{3}$ capitalista, definida como aquela que incorpora a ciência como fator de produção (o que rigorosamente só acontece décadas depois de Marx ter escrito essas linhas), representa a negação do trabalho no interior do próprio sistema. É da ciência posta em movimento durante o tempo de produção, e não mais do tempo de trabalho socialmente necessário na produção, que a criação da riqueza efetiva depende cada vez mais. Essa negação progressiva do trabalho ainda no seio do capitalismo traz muitas consequiências. Em primeiro lugar, a distinção entre trabalhadores produtivos, reduzidos a vigias, e trabalhadores improdutivos interiores à produção se torna tênue, ou antes, o trabalho produtivo se aproxima morfologicamente do improdutivo, sem com ele se confundir. Mas só o trabalho produtivo do vigia se aproxima do trabalho improdutivo. O "trabalho" portador do conhecimento científico, executado primordialmente nos Departamentos de Pesquisa e Desenvolvimento, não.

Marx não conheceu o exército de homens de ciência (cientistas, engenheiros e técnicos) contratado pelo capital. Não podia, portanto, prever as consequiências da internalização e mecanização do processo de inovação tecnológica promovido pela superindústria (fato só descrito por Schumpeter em 1942). Entre outros desdobramentos, na superindústria, o "trabalho" portador do conhecimento científico já não é mais trabalho simples potenciado. Se na grande indústria a redução do trabalho qualificado a trabalho simples já era complexa, ainda que se estabelecesse que a lei do valor antes exigia esta redução do que a pressupunha, na superindústria esta redução, dada a negação progressiva do trabalho como fundamento da riqueza, está excluída. A rigor, na superindústria, o "trabalho" portador do conhecimento científico não é sequer trabalho. É, preferencialmente, atividade.

É como se a posição da ciência estabelecesse uma segunda diferença entre trabalho simples e trabalho qualificado (que deixa de ser trabalho e passa a ser atividade), determinando uma contradição entre eles. Por certo, uma contradição diferente daquela que existe entre o trabalho simples e o trabalho (na verdade, função e não trabalho) de gerência, pois o último está ligado com a exploração, o que não é o caso de uma atividade inovadora. Pode até continuar existindo, no interior da superindústria, o clássico trabalho qualificado enquanto trabalho simples potenciado - como parece ser o caso do trabalho na organização toyotista -, mas o que estamos discutindo nesse momento é a incorporação da atividade científica (que passa a fator de produção) para o interior do universo produtivo, atividade que não se confunde com trabalho.

E os critérios para distinguir uma atividade inovadora de um trabalho qualificado são os seguintes. 1) Em primeiro lugar, a atividade inovadora não tem relação com o tempo de trabalho, embora exercida durante o tempo de

${ }^{3}$ Prefiro o termo superindústria à pós-grande indústria para evitar confusão com o termo pós-industrial. trabalho. Em outras palavras, o agente inovador, ao contrário do trabalhador qualificado, não tem jornada de trabalho. Ele pode até ser obrigado a bater o ponto, para efeitos legais, mas, a rigor, não tem jornada fixa. Isto só é possível porque os agentes envolvidos com o processo de inovação exercem atividades 
de cunho teórico abstrato, dos técnicos até os cientistas, passando pelos engenheiros. Suas atividades incomodam-lhes o sono, perturbam suas férias etc., o que não significa necessariamente que elas não lhes sejam prazerosas. Não se aplica aqui o velho chavão levar-trabalho-para-casa, no sentido de levar material para manusear, sejam fichas, livros contáveis, registros, cálculos etc. Esses agentes inovadores não levam trabalho para casa. O "trabalho", de certa maneira, os acompanha. Se o trabalhador simples, regra geral, vende ao capital sua força física, e o trabalhador qualificado, sua força mental, os agentes inovadores vendem sua força anímica. 2) Em segundo lugar, o padrão de reprodutividade dessa força produtiva guarda mais relação com o antigo virtuose medieval do que com o trabalhador moderno. O processo de reprodução já não é tão anônimo. A rigor, o tipo ideal de agente inovador é o pós-graduado que se submeteu à uma orientação pessoal de alguém que detém uma parcela de conhecimento não totalmente socializado (saber de fronteira), seja por conta do nível de profundidade, seja por conta do grau de especialização. Há, por certo, muitos agentes inovadores autodidatas ou que não contaram com um apoio pessoal à moda da relação mestre-aprendiz medieval ou, ainda, que não contaram com nenhum apoio institucional, estatal ou privado. Esses casos, não obstante, tendem a se tornar cada vez mais raros. 3) Em terceiro lugar, o rendimento de um agente inovador, apesar da forma que assume, não é, a rigor, salário. Esse rendimento, aliás, guarda algumas semelhanças com a renda fundiária. Da mesma forma que a propriedade fundiária é o outro do capital (seu pressuposto) e a renda fundiária é a contrapartida do monopólio da classe proprietária da terra, a ciência é o outro do trabalho (posto pelo capital) e a "renda do saber" é a contrapartida da posse (oligopolística) de conhecimento relativamente exclusível (excludable), para usar um jargão dos economistas (sobre isso, diremos um pouco mais, abaixo). Tecnicamente, um bem exclusível é aquele que o proprietário pode evitar que outros o usem. Um bem relativamente exclusível é um conceito análogo aplicável ao caso de uma situação oligopolística. O que torna o saber de fronteira, incorporado na tecnologia de ponta, um bem relativamente exclusível é o fato de que o acesso a ele e, portanto, sua oferta são, por definição, limitados. Em outras palavras, está-se se defendendo a hipótese de que, sob a superindústria capitalista, a fronteira do saber move-se numa velocidade superior àquela do processo de socialização do saber. 4) Em quarto lugar, a atividade inovadora, ao contrário do trabalho qualificado, não produz valor. Marx, corretamente, nas citações acima, declara a ciência fundamento da riqueza, e não do valor, e identifica a posição do trabalho social na forma da oposição entre capital e trabalho, e não qualquer outra oposição, como o último desenvolvimento da relação valor. $O$ fato de o capital internalizar a ciência ao processo produtivo, contratando agentes inovadores com esse objetivo, fato estranho ao século XIX, não muda esse aspecto da questão. Sem dúvida, o resultado da atividade de pesquisa e desenvolvimento se incorpora às mercadorias. Mas ela não é uma atividade produtiva, no sentido exato da 
palavra. Ela não produz mercadorias, embora funcione como promotora do aperfeiçoamento do processo de produção de mercadorias. Podemos até utilizar aqui, num sentido muitíssimo menos amplo, o conceito de meta-trabalho ou trabalho reflexivo de Claus Offe (cf. 1989; 1991). Habermas, em Crise de legitimação do capitalismo tardio, se dá conta da complexidade do problema, sem, contudo, resolvê-lo: "o trabalho reflexivo, diz ele, não é produtivo num sentido da produção direta da mais valia. Mas não é também improdutivo; pois então não teria efeito líquido na produção de mais valia" (Habermas, 1994, p. 75-76).

Quanto a mim, prefiro afirmar que, embora a internalização da Ciência ao universo produtivo não comprometa a teoria do valor trabalho, o mesmo não se pode dizer da teoria dos preços, pelo menos dos preços daqueles novos produtos que o capitalismo despeja diariamente no mercado. O processo de inovação tecnológica que, nos tempos de Marx, podia ser visto como uma sucessão de pontos discretos relativamente visíveis, tornou-se, com a internalização da ciência como fator de produção, um processo contínuo. Quando um certo quantum de conhecimento relativamente exclusível incorpora-se numa nova mercadoria, ela goza do mesmo grau de irreprodutibilidade daquele fator de produção que a concebeu. Até que esse conhecimento relativamente exclusível deixe de sê-lo, os preços das novas mercadorias sofrem uma distorção na exata medida da excludibilidade do saber que elas comportam. Dessa "distorção", que representa uma segunda negação da lei do valor, apropriam-se os capitalistas proprietários dos "meios de produção da ciência" e os agentes inovadores que os põem em marcha. E a forma da divisão entre eles atende mais a critérios extra-econômicos que econômicos: expectacionais, idiossincráticos, pessoais etc. Isso vem confirmar a tese de que "renda do saber" não é salário.

Por certo, a inovação tecnológica e o lucro extraordinário dela decorrente são velhos conhecidos da teoria marxista. Entretanto, o novo na superindústria é que o lucro extraordinário torna-se um "fluxo ordinário", e isso graças à ação de pessoas contratadas diretamente pelo capital para essa função. Assim, o extraordinário torna-se "ordinário", mas só como contrapartida de ser compartilhado: o capital paga o preço, certamente inferior ao ganho, de não mais se apropriar dele exclusivamente; em compensação, sente o aconchego da sua presença permanente.

${ }^{4}$ Veja-se, por exemplo, o elegante modelo matemático neoclássico, desenvolvido pelo economista neo-schumpeteriano Paul Romer em Endogenous technological change (1990).
Essas considerações deixam claras as divergências que mantenho com alguns dos teóricos já mencionados. O conceito de habilidade vendável, que Giddens empresta de Weber, e o conceito de skill, tal como usado por Wright, tornam-se mais rigorosos, diria até compreensíveis, a partir do conceito de conhecimento relativamente exclusível, uma variante do conceito utilizado pelos economistas ${ }^{4}$. Ao contrário desses teóricos, porém, não vejo razão para definir a classe que detém esse conhecimento como uma classe média. A totalidade dos agentes inovadores merece a denominação de classe por deter aquilo que deixa de ser simples produto social para se tornar mais um fator de 
produção. Como as demais classes, ela são a expressão imediata de (novas) relações de produção (postas pelo capital). Mas essa classe é simplesmente outra classe e, a título nenhum, encontra-se no meio de quaisquer outras duas.

Disso tudo decorre também minhas divergências com Mallet e o primeiro Gorz. Não se pode classificar essa classe como uma das categorias que compõe uma suposta nova classe trabalhadora. Para mim, essa classe é distinta da classe dos trabalhadores assalariados pelo simples fato de não vender propriamente força de trabalho, como espero ter deixado claro acima. A natureza do contrato que esta classe estabelece com a classe dos capitalistas é de natureza distinta. Se, por um lado, a relação entre agentes inovadores envolve o conceito de alienação (tanto quanto a relação entre capitalistas e trabalhadores), por outro, a relação entre agentes inovadores e capitalistas não envolve a noção de exploração (tanto quanto a relação entre capitalistas e proprietários fundiários).

Das tendências até aqui apresentadas, podemos inferir que o trabalho é negado em pelo menos quatro níveis distintos. 1) O crescimento do lumpemproletariado representa a negação do trabalho numa esfera que é exterior ao sistema. 2) O crescimento do número de trabalhadores improdutivos exteriores à produção representa a negação do trabalho numa esfera que embora exterior ao sistema, pertence à exterioridade no sistema. 3) $\mathrm{O}$ crescimento do número de trabalhadores improdutivos que se vendem ao capital representa uma negação parcial do trabalho produtivo já no interior do sistema. 4) Com a posição dos homens de ciência como agentes da produção, o trabalho perde centralidade no interior da própria produção.

Os sociólogos dividem-se em relação à atenção que dedicam a cada um desses fenômenos. Há quem prefira privilegiar o primeiro fenômeno, como recentemente Gorz, alargando o conceito de lumpem, por meio do conceito de não-classe de não-trabalhadores. Outros preferem dedicar a este aspecto particular somente alguns comentários sobre os programas de renda mínima garantida para os excluídos da sociedade do trabalho. Alguns mesclam o segundo e o terceiro fenômenos para cunhar o conceito de classe de serviço (Renner). Outros, o terceiro e o quarto, para cunhar o conceito de nova classe operária (Mallet). Alguns chegam a mesclar os três últimos para caracterizar a chamada sociedade pós-industrial (Bell, Touraine, Offe). Para mim, tratamse de fenômenos distintos e igualmente importantes, não obstante estarem os três primeiros fundamentados exclusivamente no último.

Para perceber melhor esse movimento, vejamos, ainda no âmbito da discussão concernente ao conceito de classe em si, como as coisas se passam do ponto de vista dinâmico. As tendências estudadas até aqui foram analisadas do ponto de vista de estática, comparativamente à teoria marxista tradicional. Discutiu-se, particularmente, os aspectos lógicos da questão. Contudo, não se descreveu o processo por meio do qual se chegou à estrutura de classes contemporânea.

O primeiro ponto a abordar, num contexto dinâmico, diz respeito à 
questão distributiva. Sabe-se que nos textos de Marx há uma diferença de abordagem dessa questão. Em $O$ capital, Marx analisa o problema do ponto de vista da tendência objetiva do sistema, estando as classes em inércia. Em Salário, preço e lucro, Marx estuda a distribuição, já considerando os efeitos da luta de classes. É verdade que em $O$ capital há pelo menos uma exceção a esta regra, concernente à determinação da jornada de trabalho. Neste caso, a luta de classes é inserida no plano do discurso de $O$ capital. Mas isso é feito por uma razão particular. "O capitalista, diz Marx, afirma o seu direito como comprador, quando procura fazer a jornada de trabalho tão longa quanto possível, e quando possível, de uma jornada de trabalho, duas. Por outro lado, a natureza específica da mercadoria vendida contém uma limitação de seu consumo pelo comprador, e o trabalhador afirma seu direito como vendedor, quando quer limitar a jornada de trabalho a uma grandeza normal determinada. Assim, há uma antinomia, direito contra direito, ambos igualmente legitimados pelo intercâmbio de mercadorias. Entre dois direitos iguais, conclui Marx, decide a violência" (apud Fausto, 1987, p. 119, nota). Ora, aqui não há propriamente luta de classes, uma vez que é a própria lógica do intercâmbio de mercadorias que coloca o trabalhador frente ao capitalista de igual para igual. A "luta" aparece para resolver uma antinomia das leis do sistema.

Com o salário, ou seja, o preço da mercadoria força de trabalho, as coisas não se passam assim. O preço da força de trabalho é determinado por uma lei geral: como qualquer mercadoria, seu preço é determinado pelo tempo de trabalho necessário a sua reprodução. A luta que almeja um aumento do preço da força de trabalho para além do estabelecido pela lei geral não vem resolver uma antinomia do sistema, mas subverter essa lei geral. "Sem dúvida, como ensina Fausto, essa lei introduz um 'elemento histórico e moral'. Mas, este é a sua maneira também inerte, porque remete ao 'nível de civilização de um país' inclusive e essencialmente aos 'hábitos e exigências vitais com que se formou a classe dos trabalhadores livres"' (Fausto, 1987, p. 121).

Assim, o discurso de $O$ capital contempla, a partir do progresso técnico, dois vetores (exclusive a luta de classes) na determinação do salário: por um lado, barateia as mercadorias que garantem a reprodução da força de trabalho, o que aumentaria o poder de compra do salário real; por outro lado, aumenta a oferta da mercadoria força de trabalho, o que provocaria sua desvalorização. Respeitada a lei geral do sistema, entretanto, não há dúvida de que a acumulação de riqueza, de um lado, implica acumulação de pobreza, de outro. Mas isso, do ponto de vista da tendência objetiva. Quando Marx introduz, em Salário, preço e lucro, o elemento luta de classes na discussão sobre salário, ele, aparentemente, abre espaço para a possibilidade de que a luta entre trabalhadores e capitalistas pudesse não ser inglória para os primeiros. Marx vislumbra, como caso limite, a hipótese do trabalhador conseguir não só um aumento do salário real, mas também a manutenção do valor da força de trabalho. Num contexto em que as mercadorias são barateadas pelo progresso tecnológico, isto representaria um enriquecimento absoluto do 
trabalhador. Esse caso limite proposto por Marx foi realmente o que aconteceu nos países capitalistas avançados. E o que parece ter tornado o caso limite um caso padrão foi a velocidade do progresso por meio da transformação da ciência em fator de produção. A partir daí, a luta distributiva passou a ser muito mais custosa para o capital, e sua contrapartida, a pacificação dos conflitos distributivos, tornou-se um bom negócio.

Com isso, muitas hipóteses inverossímeis nos tempos de Marx tornaram-se realidade. Mesmo no começo do século, dificilmente poderia se imaginar uma sociedade de consumo de massa nos moldes das atuais. Discutiam-se teses como as de crise por insuficiência de consumo (Rosa Luxemburg) ou a de produção de máquinas por máquinas (Tugan-Baranowsky). A revolução keynesiana que concebeu a insuficiência de demanda por conta da volubilidade do investimento (e não do consumo) só aparece em 1936 (data da publicação da Teoria geral de Keynes).

Sociedade de consumo, em geral, todas são. A expressão é aqui utilizada para caracterizar uma situação inédita na história na qual o rendimento da classe dominada compra cada vez mais valores de uso. Isso evidentemente não implica necessariamente maior satisfação, já que nada se disse a respeito do que o salário não compra; isto quer dizer: a satisfação só aumentaria indubitavelmente caso o nível de necessidades permanecesse constante ou aumentasse menos do que o poder de compra do salário medido em valores de uso, o que não parece ser o caso. Mas ainda assim, nada disso modifica a novidade histórica dessa situação.

Na sociedade de consumo, o trabalhador, como em todas as sociedades, utilizará seu rendimento para dispor daqueles bens, ditos de primeira necessidade, que garantem a reprodução da sua capacidade de trabalho: habitação, vestuário, alimentação. Mas, diferentemente das outras sociedades, o trabalhador dos países capitalistas avançados podem vestir-se melhor, comer mais e melhor, morar melhor, comprar supérfluos, investir no seu próprio lazer ou ainda poupar. As conseqüências óbvias desse aumento de disponibilidade material das massas trabalhadoras só poderiam ser uma hipertrofia do setor comercial e financeiro, uma hipertrofia do escritório da indústria e o fortalecimento igualmente imprevisto da produção capitalista de mercadorias imateriais.

Uma sociedade de consumo de massa requer, em primeiro lugar, meios de distribuição de massa. E dada as defasagens de racionalização do setor de distribuição em relação ao setor de produção, o primeiro experimenta uma hipertrofia em relação ao último. O progresso técnico na indústria e principalmente na agricultura propiciaram uma poupança significativa do fator trabalho na produção da maioria dos bens materiais. A produção agrícola por habitante aumentou significativamente ao mesmo tempo em que a parcela da população empregada no campo caiu drasticamente. Na indústria, embora a proporção dos trabalhadores em relação ao total da força de trabalho tenha se mantido constante (cerca de 1/3), o aumento da produtividade do trabalho 
também foi estupendo. Do lado da distribuição, entretanto, o progresso nesta área tem sido bem mais lento. Apesar de que até alguns economistas schumpeterianos, numa crítica ao mestre, terem despertado a atenção para o fenômeno da inovação nas áreas administrativas em geral, o fato inquestionável é que este tipo de inovação acontece mais raramente e tem um menor alcance que o progresso técnico na produção propriamente dita. Além disso, o setor comercial enfrenta um tipo de problema menos frequiente no âmbito da produção. O industrial, em condições normais, planeja o volume a ser produzido num determinado período de tempo e distribui a produção por esse período de uma forma regular, considerando, é claro, descanso remunerado, férias, adicional por horas extras trabalhadas etc. Dessa forma, o industrial procura dimensionar otimamente a planta e, principalmente, o emprego, mesmo sabendo que as encomendas do setor de distribuição, composto de uma rede de varejistas e atacadistas, podem flutuar ao longo do tempo. Quando o industrial não pode impor ao setor distribuidor um regime qualquer de cotas, obrigando os comerciantes a manterem o ritmo de compras, ele, preventivamente, reserva um montante adequado de capital de giro, para quando as encomendas diminuírem, e conserva um volume razoável de estoques, para quando elas crescerem. Já o comerciante, por seu turno, não pode proceder exatamente da mesma maneira. Ele depende de uma variável que ele não pode controlar: o comportamento do consumidor, que é quem decide o momento e o lugar da compra. Sendo assim, ainda que ele preveja os períodos de pico e de baixa de vendas, ele é obrigado a manter, para prestar um bom serviço ao público, um aparato de atendimento superdimensionado. Pelas razões apontadas, uma sociedade de consumo de massa não poderia deixar de observar um aumento importante do emprego no setor comercial relativamente ao total dos assalariados.

No setor financeiro da economia, as coisas não se passam de forma muito diferente. Quando se diz que, na sociedade de consumo, o trabalhador compra cada vez mais valores de uso, diz-se implicitamente que o trabalhador tem uma capacidade cada vez maior de poupança. O trabalhador, pode agora, ou seja, é-lhe facultado, poupar. O salário fixado no nível de subsistência não permitiria essa possibilidade. E diante dessa faculdade, o setor financeiro, cujo crescimento Marx havia previsto, conhece uma instituição com a qual Marx não sonharia: o banco de varejo. Erige-se um sistema bancário de dimensões enormes, lançando "produtos" os mais exóticos no mercado financeiro, com o fim de captar a eventual poupança do trabalhador (e da pequena burguesia que não sai de cena). Os bancos administram fundos de pensão, fundos de ações, fundos de renda fixa, intermedeiam o lançamento de debêntures de sociedade anônimas, vendem apólices de seguros os mais variados, criam sofisticados mecanismos de crédito ao consumidor, fundos de capitalização, planos de previdência privada, além de um notável sistema de pagamento e recebimento de contas, carnês, duplicatas etc. O número de agências cresce e distribuem-se também pelos bairros residenciais, incluindo 
os periféricos. Cresce também, como consequiência óbvia, o número de trabalhadores assalariados do setor financeiro relativamente ao número total de trabalhadores assalariados.

Outro fenômeno a destacar é a hipertrofia do escritório da indústria. O brutal desenvolvimento tecnológico ao mesmo tempo que elimina, cria novos postos de trabalho, o que exige um departamento pessoal e de treinamento ágil. Novas matérias-primas são continuamente lançadas no mercado, bem como mais modernos bens de capital, o que exige um departamento de compras. O sistema bancário, como vimos, cresce. Com ele, fortalecese os mercados de ações, o de renda fixa, as movimentações interbancárias, $o$ mercado creditício etc., exigindo da empresa produtiva um atento departamento financeiro que otimize o retorno de seu portfolio de investimentos. Cresce o comércio, nacional e internacional, muitas vezes confiado à pequena burguesia (em virtude dos baixos ganhos de escala neste setor e em virtude do enorme sistema tributário e previdenciário estatal que favorece a pequena empresa sonegadora): erige-se um poderoso departamento comercial dentro das empresas produtivas. Evidentemente, parte dessas funções podem ser terceirizadas, o que, em absoluto, muda a natureza do fenômeno.

Mas há ainda outro setor da economia que cresce com a sociedade de consumo de massa: o setor de produção de mercadorias imateriais, muitas vezes erroneamente chamado de setor de serviços ${ }^{5}$ (em sentido estrito). Se aumenta o poder de compra de bens materiais e o poder de poupança do trabalhador, é claro que aumenta o poder de compra de bens imateriais, abrindose assim mais um espaço para a exploração de tipo capitalista. Neste caso em especial, vale a pena uma análise mais detida dos textos de Marx. Numa passagem ilustrativa das possibilidades de produção imaterial, Marx declara: "uma cantora que canta como um pássaro é um trabalhador improdutivo. Se ela vende seu canto é nessa medida trabalhadora assalariada ou vendedora de mercadorias. Mas a mesma cantora, contratada por um empresário que a faz cantar para ganhar dinheiro é um trabalhador produtivo, por que produz diretamente capital" (apud Fausto, 1987, p. 247). Dissecando os momentos constitutivos da passagem, percebemos quatro possibilidades distintas. A primeira, de pouco interesse, trata da produção não propriamente econômica: uma cantora que canta enquanto se banha, ou enquanto cozinha, ou para os amigos, numa festa de aniversário etc., sem dúvida produz o canto, mas numa forma não econômica. Numa segunda possibilidade, a cantora poderá cobrar para cantar, caso em que vende seu canto como um produto imaterial diretamente para o consumidor. Mas a cantora pode também (terceira possibilidade), ao invés de vender o canto como produto imaterial, vender sua força de trabalho para alguém que a utiliza improdutivamente como valor de uso, tornando-se, nesse caso, um assalariado improdutivo (exterior à produção). Por fim, a cantora pode vender sua força de trabalho a alguém que explorará seu talento com objetivo de lucro. Às três últimas possibilidades correspondem as figuras do trabalhador autônomo, do empregado doméstico e do trabalhador
5 O setor de serviços, rigorosamente falando, não produz bens materiais ou imateriais. É o caso de serviços médicos, serviços de segurança, serviços de esteticismo etc., prestados por profissionais autônomos que, regra geral, detêm os meios necessários para oferecê-los. Essas atividades, desde sempre, puderam também ser exploradas de forma capitalista, "proletarizando" aquele profissional autônomo que, ainda nessa situação, continua um prestador de serviço. Contudo, um fato que merece destaque é a recente conversão de alguns desses serviços em "mercadorias". Exemplificando: um spa, uma academia de ginástica, uma rede de hotéis etc. não mais oferecem serviços propriamente, mas vendem como mercadoria aquilo que por natureza jamais poderia ser concebido como tal: saúde, beleza, bem-estar etc. Essas empresas, com suas dezenas de "operários", funcionam quase que como 
"indústrias", nas quais o corpo é um dos insumos e esse insumo, depois de transformado por operações as mais variadas, um novo produto. Mas não só os "bens terrenos" podem ser, por assim dizer, "industrializados". "Bens soteriológicos", que sempre foram oferecidos pelos "serviços religiosos", passam a ser "produzidos". Não estamos vendo surgir, ante nossos olhos, uma verdadeira "indústria da salvação" que suplanta os "serviços de salvação" e compete com a "indústria do entretenimento"? Aqui, porém, é o espírito - que também passa pelas mais exóticas experimentações - um dos insumos do processo, e um novo destino, o produto prometido. produtivo de mercadoria imaterial, respectivamente.

Dessas três possibilidades econômicas, interessa-nos, a princípio, a última. A produção não material, explorada pelo capital, pode resultar em mercadorias que existem separadamente do produtor, podendo inclusive circular entre o ato da produção e o ato do consumo, como livros, quadros, CDs etc. (caso que oferece poucas dificuldades teóricas porque se assemelha ao caso clássico de produção material); ou pode resultar em mercadorias cujo consumo se dá no ato da produção: quando o capitalista explora o trabalho de atores teatrais, cantores, artistas de circo etc. No caso da produção capitalista não material (deixe ou não um resultado material, como na produção literária) o trabalhador contratado pelo capital é um trabalhador produtivo porque troca sua força de trabalho por uma parte do capital variável, produzindo maisvalia para ele. $\mathrm{O}$ caráter material ou não do produto é irrelevante para a caracterização do trabalho produtivo enquanto tal. Marx inclusive critica Adam Smith por ter considerado a materialidade do produto uma segunda determinação necessária do trabalho produtivo, atribuindo essa sua postura a uma concepção fetichista própria ao modo capitalista de produção.

Contudo, o próprio Marx reconhece que, como a produção imaterial na maior parte dos casos não produz um resultado material, ela teria pouca importância no modo capitalista de produção. O produto imaterial, ainda que possua valor de uso e valor de troca, não podendo servir de suporte para o último, revela-se inadequado ao sistema por exigir consumo simultâneo à produção. Com efeito, das três categorias mencionadas, a do autônomo, do doméstico e do assalariado produtor de mercadoria imaterial, a teoria marxista só previu o aumento relativo da segunda (que de fato ocorreu). Quanto aos primeiros, os autônomos, que caracterizam-se basicamente pela propriedade dos meios de produção (o barbeiro proprietário do salão, a costureira proprietária da máquina de costura, o médico proprietário da clínica etc.), Marx previu sua diminuição por meio de um processo de assalariamento (que também ocorreu) que operou de forma muito variada e muitas vezes velada (caso dos planos de saúde que proletarizam os médicos sem lhes desincumbir do encargo de manter seus consultórios; caso da costureira que é "presenteada", em sua casa, com uma máquina nova em troca de uma remuneração por peça que lhe rende mais que um salário, mas poupa o capitalista dos encargos trabalhistas etc.)

Não obstante os acertos de Marx quanto aos autônomos e domésticos, a sociedade de consumo, no que toca à produção capitalista de mercadorias imateriais, mudou um pouco o rumo das coisas. O maior poder de compra do trabalhador, medido em valores de uso, aumentou a demanda por esse tipo de mercadoria, dando ensejo à exploração de tipo capitalista de uma "indústria" de lazer e entretenimento sem precedentes na História, o que elevou muito o número de trabalhadores assalariados nessas atividades exploradas pelo capital. Mas esse resultado está longe de ser o mais importante. Mais do que sobre a teoria de classes, a chamada "indústria cultural" teve um 
efeito perturbador sobre a teoria da consciência de classe, obrigando Adorno e Horkheimer, seguidos por Habermas, a modificar a teoria de Lukács.

Além dessas alterações na composição interna da classe dos trabalhadores assalariados (pois como vimos, essa classe é formada, não só pelos operários, mas igualmente pelos trabalhadores empregados pelo capital comercial e financeiro ou pelo capital industrial para a execução de tarefas comerciais ou financeiras, bem como os trabalhadores empregados pelo capital para a produção de bens imateriais), temos uma outra alteração importante concernente a uma das categorias que compõem a camada dos trabalhadores assalariados exteriores à produção, qual seja, a dos funcionários públicos.

Com a sociedade de consumo nasce a figura do contribuinte. Tanto quanto a palavra consumo ou consumidor, a palavra contribuinte está sendo usada aqui numa acepção particular. No capitalismo clássico, os impostos que recaíam sobre os salários o faziam de uma forma sempre indireta. Geralmente, o Estado taxava os gêneros de primeira necessidade, encarecendoos. Imposto direto sobre o contra-cheque era coisa, salvo engano, inexistente. Com o advento da sociedade de consumo, contudo, criaram-se as condições políticas para que o imposto de renda afetasse uma parcela significativa da classe trabalhadora. Quem pode se dar ao luxo de consumir supérfluos ou mesmo poupar, pode igualmente pagar impostos. Nesse sentido, se, de uma lado, o trabalhador virou consumidor, de outro, o cidadão virou contribuinte. A contrapartida disso foi que o Estado passou a assumir uma série de tarefas que, ou não eram rentáveis para a iniciativa privada, ou não deviam sê-lo, aos olhos da opinião pública. Além dos gastos de defesa externa (exército), manutenção da ordem interna (polícia), administração da justiça, relações exteriores e outras funções clássicas, o Estado criou uma estrutura para prestar serviços públicos, especialmente nas áreas de educação e saúde, áreas que consomem cerca de $50 \%$ do orçamento público (federal, estadual e municipal) de um país como os Estados Unidos, orçamento que consome cerca de $30 \%$ do PIB! Como conseqüência, verificou-se um notável aumento do número de funcionários empregados pelo Estado, sendo que em 1970, esse número já chegava a quase $1 / 6$ da força de trabalho total.

Todas essas mudanças de forma por que passou o capitalismo avançado assentam-se, como já disse, numa mudança essencial: a internalização e rotinização do processo de inovação tecnológica. A pacificação da questão distributiva, o crescimento do comércio e do sistema financeiro, o aparecimento da "indústria" do lazer e do entretenimento, bem como o advento e estabilização do Welfare State, explicam-se a partir daquele fenômeno, descrito pela primeira vez por Schumpeter. Mas a operacionalização dessa mudança só foi possível graças a drásticas medidas de cunho material. As empresas passaram a investir um volume enorme de recursos em pesquisa e desenvolvimento. Os departamentos de $\mathrm{P} \& \mathrm{D}$ criados para esse fim acolheram um contingente expressivo de cientistas, engenheiros e técnicos incumbidos de transformar o outrora discreto processo de destruição criativa num processo contínuo e 
rotineiro. "Em 1920, conta-nos Braverman, havia [nos Estados Unidos] talvez 300 desses laboratórios [de pesquisa] de empresa, e em 1940, mais de 2200. Daí por diante, empresas com um ativo tangível acima de 100 milhões de dólares tinham um pessoal de pesquisa de 170 em média, e as que possuíam ativo acima de um bilhão de dólares empregavam em média 1.250 pesquisadores. Os laboratórios da Bell Telephone, empregando acima de 5.000 era, longe, a maior organização de pesquisa do mundo" (Braverman, 1987, p. 144). Hoje, os Laboratórios Bell contam com cerca de 30.000 pesquisadores espalhados pelos 5 continentes.

Os dados de 1960 do recenseamento americano revelam que cerca de $3 \%$ da população era composta por cientistas, engenheiros e técnicos, metade dos quais empregados pela indústria manufatureira, sendo que desses, 30\% estavam diretamente envolvidos com atividades de pesquisa e desenvolvimento. Tomando-se a população economicamente ativa, tem-se que mais de 1,5\% da força de trabalho total era composta por agentes inovadores contratados exclusivamente pelo capital, ou seja, excluindo-se o "exército científico de reserva" empregado pelo Estado e pelas universidades (ver Daniel Bell). Isso significa uma proporção de mais de 1 agente inovador para cada 25 operários ou para cada 7 trabalhadores em escritório empregados pela indústria!

Portanto, da análise das classes que acabamos de empreender, penso ser possível identificar quatro classes distintas na sociedade superindustrial: 1) a classe constituída pelos proprietários do capital, pelos funcionários do capital (alta gerência) e pelos proprietários fundiários; 2) a classe dos agentes sociais inovadores, portadores do conhecimento científico-tecnológico aplicado à produção. Aqui uma observação se faz necessária. Muito freqüentemente, essa classe está envolvida num processo de inovação tecnológica, em geral, executado em departamentos específicos. Mas, com o crescimento do trabalho em escritório, não raramente encontram-se, dentro das empresas, agentes inovadores atuando na área de inovações administrativas (esse fenômeno recente foi observado até por discípulos de Schumpeter, que o criticam nesse particular): esses elementos, evidentemente, compõem a classe em questão. Além disso, temos o "exército científico de reserva", composto por professores universitários, pesquisadores de instituições públicas e privadas, e afins. Notese que, diferentemente do caso dos trabalhadores assalariados, não há membros da classe tecno-científica exteriores à produção. Do ponto de vista teórico, inclusive econômico, importa menos a natureza de seu rendimento do que a função social que exercem. E só uma teoria ingênua poderia enfocar instituições como, por exemplo, a Universidade do ponto de vista exclusivo da reprodução simbólica da sociedade; 3 ) a classe dos trabalhadores assalariados interiores à produção. E aqui é mister distinguir produtivos e improdutivos, qualificados, semi-qualificados e não-qualificados, empregados, subempregados e desempregados eventuais; e 4) os desclassificados, ou seja, a não-classe dos nãotrabalhadores (num sentido mais restrito que o de Gorz) composta pelos elementos heterônomos da sociedade. Aceito de Gorz, como se vê, a sugestão 
de tratar uma não-classe como classe porque, com efeito, o não-rendimento dessa categoria é também uma consequiência imediata das relações de produção, tanto quanto o salário ou o lucro. Ao lado dessas quatro grandes classes, parece-me importante considerar, para fins analíticos, três camadas sociais que, a rigor, não pertencem a qualquer das classes sociais mencionadas: a dos domésticos (que vendem sua força de trabalho como valor de uso), a dos autônomos (que vendem bens e serviços produzidos com meios próprios) e a dos funcionários públicos.

Recebido para publicação em junho/1997

HADDAD, Fernando. Work and social classes.Tempo Social; Rev. Sociol. USP, S. Paulo, 9(2): 97123, october 1997.

ABSTRACT: Exposition, discussion and refutation of the main attempts of actualizing marxist class theory and a posterior reevaluation of this theory taking into account the transformation of Science into a factor of production and of the possible centrality-loss of work in the productive process, based on the logic interpretations of Marx's work made by Ruy Fausto.

UNITERIMS: social classes, work, science, marxism.

\section{REFERÊNCIASBIBLIOGRÁFICAS:}

Bell, D. (1977) O advento da sociedade pós-industrial. São Paulo, Cultrix.

Braverman, H. (1987) Trabalho e capital monopolista. Rio de Janeiro, Guanabara.

DAHRENDORF, R. (1982) As classes e seus conflitos na sociedade industrial. Brasília, Editora da Universidade de Brasília.

Fausto, R. (1983) Marx: lógica e política. Tomo I. São Paulo, Brasiliense. . (1987) Marx: lógica e política. Tomo II. São Paulo, Brasiliense. (1989) A “pós-grande indústria” nos Grundrisse (e para além deles). Lua Nova, 19, novembro.

Galbraith, J. K. (1985) O novo estado industrial. São Paulo, Nova Cultural. Giannotti, J. A. (1985) Origens da dialética do trabalho. Porto Alegre, LP\&M. . (1984) Trabalho e reflexão. São Paulo, Brasiliense. 
. (1990) A sociabilidade travada. Novos Estudos Cebrap, 28.

GidDEns, A. (1975) A estrutura de classes das sociedades avançadas. Rio de Janeiro, Zahar Editores.

Gorz, A. (1968) A estratégia operária e neocapitalismo. Rio de Janeiro, Zahar Editores.

. (1987) Adeus proletariado. Rio de Janeiro, Forense Universitária.

. (1988) Métamorphoses du travail quête du sens. Paris, Galilée.

Habermas, J. (1994) A crise de legitimição no capitalismo tardio. Rio de Janeiro, Tempo Brasileiro.

HadDAD, Fernando. (1992) O sistema soviético. São Paulo, Scritta.

KonRÁD, G. \& SzELÉnYI, I. (1979) The intellectuals on the road to class power. New York, Harcourt Barce Jovanovich.

Lukács, G. (1974) História e consciência de classe. Porto, Publicações Escorpião.

. (1979) Ontologia do ser social: os princípios ontológicos fundamentais de Marx. São Paulo, Livraria Editora Ciências Sociais.

. (1981) Ontologia dell'essere sociale: il lavoro. Roma, Editori Reuniti.

Mallet, S. (1963) La nouvelle classe ouvrière. Paris, Éditions du Seuil.

MARX, Karl. (1973) Elementos fundamentales para la crítica de la economia política (Borrador). 2 vols. Buenos Aires, Siglo Vintiuno.

. (1980) O capital. 6 vols. São Paulo, Difel.

. \& Engels, F. (1980) Obras escolhidas. 3 vols. São Paulo, AlfaOmega.

. (1985) Formações econômicas pré-capitalistas. São Paulo, Paz e Terra.

. (1988) Salário, preço e lucro. In:

Vol IV. São Paulo, Nova Cultural. . Coleção os Pensadores,

Offe, C. \& Frank, J. \& Vogt, W. (1980) Estado e capitalismo. Rio de Janeiro, Tempo Brasileiro.

OfFe, C. (1989a) Capitalismo desorganizado. São Paulo, Brasiliense.

. (1989b) Trabalho e sociedade. Vol. 1. Rio de Janeiro, Tempo Brasileiro.

. (1991) Trabalho e sociedade. Vol. 2. Rio de Janeiro, Tempo Brasileiro.

(1994) Problemas estruturais do estado capitalista. Rio de Janeiro, Tempo Brasileiro. 
Romer, P. M. (1990) Endogenous technological change. Journal of Political Economy. 98(5): S71.

Schumpeter, J. A. (1982) A teoria do desenvolvimento econômico. São Paulo, Abril Cultural.

. (1984) Capitalismo, socialismo e democracia. Rio de Janeiro, Zahar.

Touraine, A. (1970) A sociedade post-industrial. Lisboa, Moraes.

Weber, M. (1992) Economia y sociedad. México, Fondo de Cultura Económica.

Wright, E. O. (1977) What is the middle about the middle class? In: RoEMER, J. Analitical marxism. Cambridge, Cambridge University Press. 
